DOI: https://doi.org/10.47405/mjssh.v6i12.1192

\begin{tabular}{|c|c|}
\hline & Malaysian Journal of Social Sciences and Humanities (MJSSH) \\
\hline Malaysian Journal of & Volume 6, Issue 12, December 2021 \\
\hline (MJ-sSH) & e-ISSN : 2504-8562 \\
\hline & $\begin{array}{l}\text { Journal home page: } \\
\text { www.msocialsciences.com }\end{array}$ \\
\hline
\end{tabular}

\title{
Tahap Pembacaan Pelajar KUIS dan Kesannya Terhadap Tahap Emosi Sepanjang Tempoh Perintah Kawalan Pergerakan
}

\author{
Zurina binti Abdullah1, Marziana binti Abdul Majid ${ }^{1}$ \\ ${ }^{1}$ Kolej Universiti Islam Antarabangsa Selangor (KUIS), Selangor, Malaysia \\ Correspondence: Zurina binti Abdullah (zurinaabdullah@kuis.edu.my)
}

\begin{abstract}
Abstrak
Kajian ini dilakukan untuk mengetahui tahap pembacaan mahasiswa/i Kolej Universiti Islam Antarabangsa Selangor (KUIS) dan kesannya terhadap emosi mereka sepanjang tempoh Perintah Kawalan Pergerakan (PKP) yang telah bermula sejak 18 Mac 2020. Tempoh masa yang diambil melibatkan PKP Fasa 1 hingga Fasa 3. Kajian yang bersifat kualitatif ini dilakukan menggunakan borang soal selidik. Seramai 54 orang responden telah menjawab soal selidik yang terdiri daripada pelbagai bidang pengajian. Responden yang terlibat merupakan para pelajar yang terkandas di KUIS disebabkan PKP dan ada antara mereka yang perlu menghadapi peperiksaan akhir secara dalam talian. Dapatan kajian ini menunjukkan para mahasiswa/i lebih kerap membaca dalam tempoh PKP kerana ingin mendapatkan maklumat terkini dan juga menghilangkan kebosanan. Bahan bacaan yang menjadi pilihan utama mereka adalah bersifat separa ilmiah dan pilihan utama mereka ialah media sosial seperti facebook, instagram dan twitter, alquran dan akhbar dalam talian. Aktiviti membaca juga ternyata dapat memberi kesan positif dalam menguruskan emosi mereka. Responden bersetuju bahawa aktiviti membaca dapat menghilangkan kebosanan mereka sepanjang berada di kolej kediaman, tidak membuatkan mereka berasa tersisih dan mendidik mereka untuk melakukan aktiviti yang lebih berfaedah. Selain itu, kajian ini turut meninjau permasalahan yang dihadapi oleh mahasiswa/i untuk membaca dalam tempoh PKP ini.
\end{abstract}

Kata kunci: tahap pembacaan, kesan membaca, perintah kawalan pergerakan, mahasiswa/i KUIS, soal selidik

\section{KUIS Students' Reading Levels and Its Effects on Emotional Levels Throughout Movement Control Order}

\begin{abstract}
This study was conducted to find out the reading level of students of Selangor International Islamic University College (KUIS) and its effect on their emotions during the period of Movement Control Order (MCO) which has started on March 18, 2020. The time taken involves MCO Phase 1 to Phase 3 This qualitative study was conducted using a questionnaire. A total of 54 respondents answered the questionnaire consisting of various fields of study. The respondents involved students who were stranded in KUIS due to MCO and some of them have to face the final exam online. The findings of this study show that students read more often during the MCO period because they want to get the latest information and also get rid of boredom. The reading material that is their main choice is semiscientific and their main choice is social media such as Facebook, Instagram and Twitter, the Quran, and online newspapers. Reading activities also turn out to have a positive effect on managing their
\end{abstract}


emotions. Respondents agreed that reading activities could relieve their boredom throughout their stay in the residential college, not make them feel excluded, and educate them to do more rewarding activities. In addition, this study also examines the problems faced by students to read during this MCO period.

Keywords: reading level, reading effect, movement control order, KUIS students, questionnaire

\section{Pengenalan}

Wabak Covid-19 telah mula menyerang seluruh dunia sejak akhir tahun 2019 sehinggalah kini. Ia telah diisytiharkan sebagai pandemik oleh Kesatuan Kesihatan Sedunia (WHO) kerana serangan hebat wabak ini ke seluruh dunia mengakibatkan kematian dalam jumlah yang besar. Wabak ini tersebar melalui rangkaian antara satu manusia dengan manusia yang lain dalam jarak dekat dan kurang satu meter sama ada melalui sentuhan, duduk bersebelahan, bersin dan sentuhan ke atas barangan yang telah disentuh oleh pesakit yang telah dijangkiti wabak ini.

Malaysia merupakan antara negara terawal yang telah mengambil tindakan proaktif dalam mengekang penularan wabak ini. Kerajaan Malaysia telah melancarkan Perintah Kawalan Pergerakan (PKP) bermula 18 Mac 2020 selama 14 hari. Dalam tempoh PKP ini, hampir kesemua organisasi terpaksa ditutup termasuklah Institusi Pengajian Tinggi (IPT). Penutupan organisasi adalah untuk mengurangkan masyarakat keluar rumah. Usaha ini dapat memutuskan rangkaian penyebaran wabak Covid-19. Penularan wabak Covid-19 ini tidak menghalang segala aktiviti manusia. Aktiviti harian masih boleh diteruskan namun perlu mengikut tatacara yang telah ditetapkan oleh Kementerian Kesihatan Malaysia (KKM) dan Majlis Keselamatan Negara (MKN). Namun, keterbatasan ini memberi impak yang besar kepada ekonomi masyarakat seterusnya memberi cabaran ke atas pengurusan emosi.

Cabaran ekonomi bermula apabila kerajaan Malaysia mengumumkan arahan PKP dengan menutup sebahagian besar organisasi dan memperkenalkan konsep bekerja dari rumah. Tidak semua pekerjaan sesuai untuk dilaksanakan di rumah seperti produksi kilang, pembersihan dan pengawal keselamatan. Disebabkan arahan PKP ini, banyak organisasi terpaksa memberhentikan pekerja untuk meminimumkan saiz organisasi lantaran tiada keperluan terhadap kakitangan. Kehilangan pekerjaan memberi tamparan hebat kepada masyarakat. Lanjutan daripada masalah ekonomi, ia memberi impak besar terhadap emosi masyarakat. Masyarakat terpaksa berkurung dan mengurangkan secara drastik aktiviti di luar rumah. Keadaan ini menyebabkan berlakunya masalah kewangan yang menjadi punca terjadinya pergaduhan dalam rumah tangga. Menurut Hemavathi et.al (dlm Abdul Rashid et. al, 2020), dalam kajiannya yang dilakukan terhadap populasi di Malaysia berhubung impak Covid-19 kepada kesihatan mental mendapati bahawa penjarakan fizikal telah memaksa individu untuk tinggal di rumah dalam jangka masa yang lama dan keadaan ini dapat menyebabkan tekanan kepada individu tersebut sekiranya suasana di rumah tersebut tidak sihat.

Menurut kajian Jiménez et al. (2018), membaca mempunyai pengaruh terhadap emosi. Apabila kita membaca buku berkisah agama, hati akan terasa ingin mendekatkan diri kepada Tuhan, membaca buku motivasi dapat meningkatkan semangat dan lonjakan kekuatan dalaman untuk mencapai kejayaan, membaca buku akademik memberi banyak fakta yang tidak diketahui sebelum ini dan begitulah jika kita membaca bahan bacaan yang lain. Membaca dapat mengalih fokus kita kepada suatu penyelesaian masalah dan tidak hanya tertumpu kepada masalah yang dihadapi. Mereka yang kurang membaca seringkali melakukan perkara-perkara yang memakan diri sendiri dek kerana tiada panduan dalam mencari penyelesaian masalah (Duval et al., 2018). Maka, aktiviti membaca bukan sahaja dapat membantu mengurus emosi malah ia memberi keupayaan interpersonal, keupayaan intrapersonal dan pengurusan tekanan (Jiménez et al., 2018; Ghabanchi \& Rastegar, 2014).

Di Kolej Universiti Islam Antarabangsa (KUIS) ketika pengumuman arahan PKP oleh kerajaan Malaysia, KUIS sedang menjalankan peperiksaan akhir semester. Oleh sebab itu, terdapat sebahagian pelajar yang tidak sempat pulang ke rumah keluarga masing-masing disebabkan tidak berkesempatan 
membeli tiket pulang dalam tempoh kecemasan dan mereka juga perlu menghadapi peperiksaan akhir secara dalam talian. Oleh yang demikian, mereka terpaksa menetap di kolej kediaman. Kajian ini dijalankan terhadap pelajar-pelajar tersebut bagi mengenal pasti kesan membaca terhadap emosi mahasiswa sepanjang menjalani tempoh PKP di kolej kediaman.

\section{Objektif Kajian}

i. Mengenal pasti bahan bacaan yang menjadi pilihan mahasiswa/i dan kadar kekerapan membaca.

ii. Mengenal pasti sama ada aktiviti membaca memberi kesan terhadap emosi mahasiswa/i sepanjang tempoh PKP.

iii. Mengenal pasti sejauh mana membaca mempengaruhi emosi positif dalam kalangan mahasiswa/i.

\section{Metod Kajian}

Kajian ini bersifat kuantitatif dan menggunakan borang kaji selidik sebagai instrumen kajian. Borang kaji selidik ini dibangunkan melalui Google Form dan diedarkan kepada responden. Soalan kaji selidik tersebut mempunyai tiga bahagian, iaitu Bahagian A: Demografi Responden, Bahagian B: Tahap pembacaan mahasiswa/i dan Bahagian C: Kesan Membaca Terhadap Emosi Responden. Soalan di Bahagian A adalah bersifat tertutup dan hanya memerlukan responden memilih pilihan jawapan yang disenaraikan manakala soalan di Bahagian B dan C adalah berbentuk Skala Likert 4 iaitu skala 1=Sangat Tidak Setuju, 2=Tidak Setuju, 3=Setuju dan 4=Sangat Setuju.

\section{Dapatan Kajian}

\section{Latar Belakang Responden}

Bagi bahagian pertama, pengkaji mendapatkan latar belakang responden bagi menganalisis maklumat peribadi responden, iaitu jantina, umur, bidang pengajian, semester dan asal. Jadual 1.1 menunjukkan analisis kekerapan responden mengikut jantina.

Jadual 1: Analisis kekerapan responden mengikut jantina

\begin{tabular}{lll}
\hline Jantina & Kekerapan & Peratus (\%) \\
\hline Perempuan & 34 & 63 \\
Lelaki & 20 & 37 \\
Jumlah & 54 & 100.0 \\
\hline
\end{tabular}

Jadual 1 menunjukkan 34 orang responden adalah perempuan dengan nilai peratusan 63 peratus manakala 37 peratus lagi responden adalah lelaki dengan jumlah 20 orang. Dapatan analisis menunjukkan perempuan melebihi lelaki sebagai responden kajian ini.

Jadual 2: Analisis kekerapan responden mengikut umur

\begin{tabular}{ccc}
\hline Umur & Kekerapan & Peratusan (\%) \\
\hline $18-20$ tahun & 8 & 14.8 \\
$21-23$ tahun & 40 & 74.1 \\
24-27 tahun & 6 & 11.1 \\
Jumlah & 54 & 100 \\
\hline
\end{tabular}

Jadual 2 menunjukkan sebahagian besar responden terdiri daripada mereka yang berumur antara 21 hingga 23 tahun, iaitu seramai 40 orang (74.1\%) diikuti mereka yang berumur di antara 18 hingga 20 
tahun, iaitu seramai 8 orang (14.8\%) manakala responden yang berumur di antara 24 hingga 27 tahun, iaitu seramai 6 orang $(11.1 \%)$. Kesemua responden adalah para mahasiswa/i daripada bidang pengajian yang berbeza dan melibatkan mahasiswa/i semester 1 hingga 8 .

Jadual 3: Analisis kekerapan responden mengikut asal.

\begin{tabular}{lll}
\hline Asal & Kekerapan & Peratusan $(\%)$ \\
\hline Selangor & 5 & 9.3 \\
Melaka & 1 & 1.9 \\
Johor & 2 & 3.7 \\
Perak & 4 & 7.4 \\
Kedah & 6 & 11 \\
Sabah & 16 & 29.6 \\
Sarawak & 5 & 9.3 \\
Terengganu & 2 & 3.7 \\
Kelantan & 10 & 18.5 \\
Pahang & 3 & 5.6 \\
Jumlah & 54 & 100 \\
\hline
\end{tabular}

Analisis kekerapan responden mengikut negeri berdasarkan Jadual 3 menunjukkan responden yang teramai adalah berasal dari negeri Sabah, iaitu seramai 16 responden (29.6\%). Hal ini kerana kebanyakan mahasiswa/i KUIS dari negeri Borneo telah menempah tiket lebih awal dan rata-rata merancang untuk pulang selepas tamat menduduki peperiksaan akhir semester. Oleh yang demikian, jumlah pelajar dari Sabah mewakili responden yang paling ramai. Responden kedua teramai didapati berasal dari Kelantan, iaitu seramai 10 responden (18.5\%) diikuti responden berasal dari negeri Kedah, iaitu 6 responden (11\%), manakala Selangor dan Sarawak masing-masing seramai 5 responden $(9.3 \%)$, dan selebihnya dari negeri-negeri lain di Semenanjung.

\section{Tahap Pembacaan Responden}

Pada bahagian B soalan-soalan yang dikemukakan adalah untuk mengenal pasti tahap pembacaan responden yang meliputi kekerapan responden membaca, pemilihan bahan bacaan dan permasalahan yang dihadapi responden yang menyebabkan mereka tidak membaca.

Responden ditanya sama ada mereka meluangkan masa dengan membaca. Seramai 48 responden $(88.9 \%)$ menjawab ya dan 6 responden $(11.1 \%)$ menjawab tidak. Seterusnya, responden ditanya apakah pilihan medium bahan bacaan yang dipilih dan responden boleh memilih lebih daripada satu medium. Pilihan yang tertinggi ialah media sosial seperti Facebook, Instagram, Twitter, iaitu seramai 50 orang (92.6\%), kedua tertinggi memilih Al-Quran, iaitu seramai 48 orang (88.9\%), ketiga adalah akhbar dalam talian seramai 36 orang $(66.7 \%)$, seterusnya buku, iaitu 24 orang (44.4\%), majalah seramai 8 orang $(14.8 \%)$, dan selebihnya medium-medium lain.

Seterusnya, responden ditanya berkenaan kategori bahan bacaan yang mereka pilih. Kategori bahan bacaan terbahagi kepada tiga, iaitu ilmiah, separa ilmiah dan bukan ilmiah atau popular. Responden boleh memilih lebih daripada satu pilihan. Hasil dapatan menunjukkan kategori separa ilmiah menjadi pilihan kebanyakan responden, iaitu seramai 48 orang, kedua kategori ilmiah seramai 36 orang dan bukan ilmiah atau popular seramai 32 orang. Sepanjang PKP ini didapati seramai 49 responden $(90.7 \%)$ membaca topik berkaitan isu semasa diikuti isu agama dengan seramai 47 responden (87\%), 37 responden $(68.5 \%)$ memilih topik berkaitan hiburan, 30 responden $(55.6 \%)$ memilih topik pendidikan, dan topik berkaitan politik dan bidang pengajian masing-masing sebanyak 27 responden (50\%) dan 22 responden $(40.7 \%)$.

Bagi mengetahui tahap kekerapan responden membaca dalam sehari, pengkaji turut bertanya kadar kekerapan responden membaca dalam sehari. Keputusan dapat dilihat dalam jadual berikut: 
Jadual 4: Analisis kekerapan responden membaca dalam sehari

\begin{tabular}{lll}
\hline Umur & Kekerapan & Peratusan (\%) \\
\hline 2 jam atau lebih & 25 & 46.3 \\
Kurang lebih 1 jam & 18 & 33.3 \\
Kurang lebih 30 minit & 9 & 16.7 \\
Kurang lebih 15 minit & 2 & 3.7 \\
Jumlah & 54 & 100 \\
\hline
\end{tabular}

Berdasarkan Jadual 4 hampir sebahagian responden, iaitu seramai 25 responden (46.3\%) telah membaca selama 2 jam atau lebih dalam sehari. Seramai 18 responden (33.3\%) didapati membaca kurang lebih 1 jam dalam sehari dan selebihnya kurang lebih 30 minit dan 15 minit. Sepanjang tempoh PKP, iaitu dalam tempoh fasa 1 hingga fasa 3 (enam minggu) para responden didapati telah membaca buku untuk meluangkan masa mereka. Bilangan buku yang dibaca sepanjang tempoh PKP dapat dilihat pada jadual berikut:

Jadual 5: Bilangan buku yang dibaca sepanjang PKP

\begin{tabular}{lll}
\hline Bilangan buku & Kekerapan & Peratusan $(\%)$ \\
\hline 0 (tidak membaca) & 8 & 14.8 \\
1 hingga 3 & 34 & 63 \\
4 hingga 6 & 5 & 9.3 \\
7 hingga 9 & 4 & 7.4 \\
10 ke atas & 3 & 5.6 \\
Jumlah & 54 & 100 \\
\hline
\end{tabular}

Dapatan yang dipaparkan dalam Jadual 5 menunjukkan lebih sebahagian daripada jumlah responden telah membaca sebanyak 1 hingga 3 buah buku sepanjang enam minggu PKP di KUIS, iaitu seramai 34 responden $(63 \%)$. Seramai 8 responden $(14.8 \%)$ didapati tidak membaca walaupun satu buah buku. Keadaan ini membawa kepada persoalan tentang punca atau faktor yang menghalang seterusnya menjadi penyebab mereka tidak membaca buku. Namun begitu, didapati terdapat 3 responden (5.6\%) yang telah membaca 10 buah buku. Keadaan ini boleh disebabkan responden berkenaan mempunyai banyak koleksi buku atau meminjam buku rakan-rakan.

Para responden didapati meluangkan masa dengan membaca disebabkan pelbagai tujuan. Berdasarkan dapatan soal selidik, tujuan utama mereka membaca adalah untuk mengurangkan tahap kebosanan, iaitu seramai 23 responden (42.6\%), diikuti untuk mencari maklumat ilmiah seramai 14 responden (25.9\%), membaca untuk tujuan santai seramai 9 responden $(16.7 \%)$, mengurangkan kerinduan terhadap keluarga seramai 5 responden $(9.3 \%)$ dan baki responden didapati tidak membaca. Seterusnya, responden telah ditanya sama ada dalam tempoh PKP berada di KUIS menyebabkan mereka lebih membaca atau tidak. Jawapan yang diberikan menunjukkan seramai 34 responden (63\%) bersetuju manakala bakinya seramai 20 responden $(37 \%)$ menjawab tidak.

Dapatan daripada jawapan ini membawa kepada persoalan seterusnya, iaitu untuk mengetahui faktorfaktor yang menghalang responden untuk membaca dalam tempoh PKP ini. Faktor tertinggi yang menjadi penghalang atau penyebab responden tidak membaca adalah kerana sifat tidak minat membaca dengan bilangan responden seramai 15 orang (27.8\%). Faktor kedua tertinggi adalah kesibukan melakukan aktiviti lain, iaitu seramai 13 responden $(24.1 \%)$, diikuti faktor capaian data internet yang perlahan seramai 10 responden (18.5), kekurangan sumber bacaan yang berkualiti seramai 8 responden (14.8\%), tiada kebenaran capaian ke pusat sumber atau perpustakaan seramai 5 responden $(9.3 \%)$ dan bakinya menjawab faktor persekitaran yang tidak selesa seramai 3 responden (5.6\%). 
DOI: https://doi.org/10.47405/mjssh.v6i12.1192

\section{Kesan Membaca Terhadap Emosi Responden}

Bahagian ini adalah untuk melihat kesan aktiviti membaca terhadap emosi responden sepanjang menjalani arahan PKP. Soalan yang dikemukakan di bahagian ini adalah berbentuk Skala Likert 4 iaitu 1=Sangat Tidak Setuju, 2=Tidak Setuju, 3=Setuju dan 4=Sangat Setuju. Namun, taburan dalam jadual berikut menyimpulkan skala 1 dan 2 sebagai tidak setuju manakala skala 4 dan 5 adalah setuju.

\section{Aktiviti membaca dapat mengurangkan kebosanan di kolej kediaman sepanjang PKP}

Jadual 6 menunjukkan majoriti responden seramai 46 orang responden $(85.2 \%)$ bersetuju bahawa aktiviti membaca dapat mengurangkan kebosanan ketika berada di kolej kediaman sepanjang PKP walaupun berjauhan dari keluarga. Hanya 8 orang responden (14.8\%) tidak menganggap aktiviti membaca dapat mengurangkan kebosanan mereka.

Jadual 6: Analisis terhadap soalan tentang membaca dapat mengurangkan kebosanan di kolej kediaman sepanjang PKP

\begin{tabular}{lll}
\hline Tahap Persetujuan & Kekerapan (N) & Peratus (\%) \\
\hline Setuju & 46 & 84.9 \\
Tidak bersetuju & 8 & 14.9 \\
\hline
\end{tabular}

\section{Aktiviti membaca dapat membuatkan saya berada dalam situasi semasa dan tidak berasa tersisih}

Jadual 7 menunjukkan majoriti responden seramai 45 orang ( $83.3 \%)$ bersetuju bahawa dengan adanya aktiviti membaca, ia membolehkan responden mengetahui perkembangan semasa dan tidak berasa tersisih dari mendapatkan sumber maklumat terkini. Namun seramai 9 orang (16.7\%) tidak bersetuju dengan pernyataan tersebut.

Jadual 7: Analisis terhadap soalan tentang aktiviti membaca dapat membuatkan responden berada dalam situasi semasa dan tidak tersisih

\begin{tabular}{lll}
\hline Tahap Persetujuan & $\begin{array}{l}\text { Kekerapan } \\
(\mathbf{N})\end{array}$ & Peratus (\%) \\
& 45 & 83.3 \\
Setuju & 9 & 16.7 \\
Tidak bersetuju & \\
\hline
\end{tabular}

\section{Saya dapat mengurus emosi dengan lebih baik kerana hasil pembacaan mendidik saya kepada perkara yang lebih bermanfaat}

Jadual 8 memaparkan majoriti seramai 49 orang responden $(90.7 \%)$ bersetuju bahawa aktiviti membaca sepanjang PKP dapat membantu mengurus emosi mereka dengan lebih baik kerana hasil maklumat yang diperolehi selepas membaca dapat membimbing responden kepada perkara yang lebih bermanfaat.

Jadual 8: Analisis terhadap soalan tentang dapat mengurus emosi dengan lebih baik kerana hasil pembacaan mendidik saya kepada perkara yang lebih bermanfaat

\begin{tabular}{lll}
\hline Tahap Persetujuan & $\begin{array}{l}\text { Kekerapan } \\
(\mathbf{N})\end{array}$ & Peratus (\%) \\
\hline Setuju & 49 & 90.7 \\
Tidak bersetuju & 5 & 9.3 \\
\hline
\end{tabular}




\section{Saya berasa letih dan berputus asa akibat tekanan perasaan apabila membaca}

Jadual 9 menunjukkan majoriti responden seramai 41 orang (75.9\%) tidak bersetuju bahawa aktiviti membaca memberi tekanan sehingga menimbulkan rasa letih dan putus asa. Hanya 13 orang responden $(24.1 \%)$ sahaja yang bersetuju dengan pernyataan tersebut.

Jadual 9: Analisis terhadap soalan saya berasa letih dan berputus asa akibat tekanan perasaan apabila membaca

\begin{tabular}{lll}
\hline Tahap Persetujuan & Kekerapan $(\mathbf{N})$ & Peratus (\%) \\
\hline Setuju & 13 & 24.1 \\
Tidak bersetuju & 41 & 75.9 \\
\hline
\end{tabular}

\section{Saya dapat menyumbang sesuatu yang bermanfaat dengan membaca dalam tempoh PKP}

Jadual 10 menunjukkan majoriti responden seramai 46 orang $(85.2 \%)$ bersetuju melalui aktiviti membaca, mereka dapat menyumbang sesuatu yang bermanfaat kepada masyarakat. Hanya 8 orang responden $(11 \%)$ sahaja yang tidak bersetuju dengan pernyataan ini.

Jadual 10: Analisis terhadap soalan saya dapat menyumbang sesuatu yang bermanfaat dengan membaca dalam tempoh PKP

\begin{tabular}{lll}
\hline Tahap Persetujuan & Kekerapan (N) & Peratus (\%) \\
\hline Setuju & 46 & 85.2 \\
Tidak bersetuju & 8 & 14.8 \\
\hline
\end{tabular}

Tempoh PKP ini dapat memberi peluang kepada saya untuk membaca buku yang tidak sempat dibaca sebelum ini

Jadual 11 memaparkan majoriti seramai 43 orang responden (79.6\%) bersetuju bahawa tempoh PKP ini dapat memberi mereka peluang untuk membaca buku yang tidak sempat dibaca lantaran kesibukan dengan kuliah, tugasan dan pelbagai aktiviti di kampus. Namun, terdapat 11 orang responden $(11.4 \%)$ tidak merasakan tempoh PKP ini merupakan peluang bagi mereka untuk membaca buku yang tidak sempat dibaca sebelum ini.

Jadual 11: Analisis Terhadap Soalan Tempoh PKP ini dapat memberi peluang kepada saya untuk membaca buku yang tidak sempat dibaca sebelum ini

\begin{tabular}{lll}
\hline Tahap Persetujuan & Kekerapan (N) & Peratus (\%) \\
& & \\
\hline Setuju & 43 & 79.6 \\
Tidak bersetuju & 11 & 20.4 \\
\hline
\end{tabular}

\section{Kesimpulan}

Hasil kajian menunjukkan tahap pembacaan mahasiswa/i KUIS dalam tempoh PKP berada dalam keadaan baik. Responden didapati cenderung untuk mengetahui isu semasa disamping mencari pengisian kerohanian dan menghiburkan diri sendiri. Keadaan ini dapat dilihat melalui jawapan responden terhadap pemilihan topik dan medium bahan bacaan. Kecenderungan untuk membaca juga berkaitan dengan emosi responden kerana sebahagian besar membaca untuk mengurangkan kebosanan 
dan juga santai. Namun, beberapa kekangan turut menjadi faktor yang menghalang responden daripada membaca.

Hasil kajian yang dijalankan ke atas responden yang menetap di kolej kediaman sepanjang PKP jelas menunjukkan aktiviti membaca memberi pengaruh positif ke atas emosi manusia walau dalam situasi yang tidak diingini seperti pandemik Covid-19. Bahan bacaan tidak semestinya berbentuk ilmiah asalkan sahaja ia dapat membantu pembaca untuk mengurus emosi dengan cara yang baik dan positif. Pemilihan bahan bacaan adalah bergantung kepada minat pembaca apatah lagi ketika kajian ini dijalankan, peperiksaan akhir semester hampir tamat. Responden mempunyai ruang masa yang banyak untuk membaca bahan bacaan santai tanpa terikat dengan tugasan akademik. Didapati kesan membaca bukan sahaja memberi maklumat terkini kepada pembaca, malah pembaca tidak berasa terasing dan disisihkan. Mereka dapat mengikuti perkembangan terkini dan boleh berkongsi maklumat bersama rakan lain malah mereka boleh mengambil langkah berjaga-jaga bagi memelihara diri daripada wabak Covid-19 ini.

\section{Rujukan}

Abdul Rashid Abdul Aziz, et.al. (2020). Wabak Covid-19: Pengurusan aspek kesihatan mental semasa norma baharu. International Journal of Social Science Research, 2(4), 156-174.

Duval, R., Moretti, et.al. (2018). An investigation of the effectiveness of TWA on reading comprehension of students with and atrisk for emotional and behavioral disorders. Revemat: Revista Eletrônica de Educação Matemática, 13(1), 1689-1699.

Ghabanchi, Z., \& Rastegar, R. (2014). The correlation of IQ and emotional intelligence with reading comprehension. Reading Matrix: An International Online Journal, 14(2), 135-144.

Jiménez, E. del P., et.al. (2018). Reading Intervention: Correlation Between Emotional Intelligence and Reading Competence in High School Students. Revista de Psicodidáctica (English Ed.), 24(1), 24 30 . 